\title{
Kum Zeminlerde İlave Düşey Gerilmenin Derinlikle Değişiminin Farkı Yöntemlerle İncelenmesi
}

\author{
Mehmet Fatih YAZICI ${ }^{1 *}$, Recep AKAN ${ }^{2}$, Siddıka Nilay KESKIN ${ }^{3}$ \\ Süleyman Demirel Üniversitesi, Mühendislik Fakültesi, Inşaat Mühendisliği, Isparta \\ (ORCID: 0000-0002-3557-7817) (ORCID: 0000-0002-9277-1659) (ORCID: 0000-0002-0367-943X)
}

\begin{abstract}
$\ddot{O} \mathbf{z}$
Bu çalışmada, yüklü alan boyutunun ve zeminin içsel sürtünme açısının zeminde meydana gelecek gerilme artışlarına etkisi araştırılmıştır. Bu amaçla farklı boyutlara sahip temeller farklı içsel sürtünme açısına sahip kum zemin üzerine oturtularak hem iki boyutlu bir sonlu elemanlar yazılımı olan Plaxis 2D ile gerçekleştirilen analizlerle hem de zemin mekaniğinde yaygın bir şekilde kullanılan analitik çözümlerle zeminde meydana gelen ilave düşey gerilmeler belirlenmiştir. Temel boyutu küçüldükçe sonlu elemanlar yönteminden elde edilen sonuçlar, zemin mekaniğinde kullanılan analitik çözümlerden elde edilen sonuçlara yaklaşmaktadır. Ayrıca zeminin içsel sürtünme açısındaki artış ile temelin köşe noktası altında meydana gelen ilave düşey gerilmeler artmakta, temelin orta noktası altında ise belli bir derinliğe kadar azalmaktadır. Genel olarak yaklaşık yöntemden elde edilen sonuçlar, sonlu elemanlar yönteminden elde edilen sonuçlar ile daha uyumlu çıkmış ve küçük temel boyutlarında bu uyum artmaktadır.
\end{abstract}

Anahtar kelimeler: İlave düşey gerilme, sonlu elemanlar yöntemi, temel boyutları, içsel sürtünme açısı.

\section{Investigation the Change of Additional Vertical Stress by Depth in Sand Soil by Different Methods}

\begin{abstract}
In this study, the effect of the loaded area size and the internal friction angle of the soil on the stress increases occurring in the ground was investigated. For this purpose, the rectangular foundations that have different dimensions rested on a sand soil which has different internal friction angles analyzed by Plaxis 2D and conventional methods. After, additional vertical stress distribution due to an external load in soil was analysed and the results obtained from conventional methods and finite element method were compared. As a result, the approximate method results generally have the best aggrement with finite element method results and while the length of foundation gets shorter this aggrement gets better. Furthermore, additional vertical stress values increase with increase of internal friction angle of soil below the corner of foundation. Below the middle of foundation, additional vertical stress values increase with increase of internal friction angle of soil up to a certain depth and after this depth additional vertical stress decreases.
\end{abstract}

Keywords: Additional vertical stress, finite elements method, foundation dimensions, internal friction angle.

\section{Giriş}

Geoteknik mühendisliğinde zeminlerin sıkışabilirliği ve zemin iksa yapıları üzerine etkiyen yatay toprak basınçları gibi problemleri analiz edebilmek için zemin profilinde belirli bir en kesitteki gerilme dağılımının bilinmesi gerekmektedir. Zeminlerde meydana gelen ilave gerilme artışlarının belirlenmesi için çeşitli yöntemler önerilmiştir. Bu yöntemler genellikle zemini elastik, izotrop, homojen ve yarı sonsuz ortam olarak kabul etmektedir. Elastik teoriden faydalanılarak oluşturulan bu yöntemler, zemine ait parametreleri dikkate almamaktadır. Buna karşılık bir dış yükleme nedeniyle zeminde meydana gelen

*Sorumlu yazar: mehmetyazici@sdu.edu.tr

Geliş Tarihi: 23.10.2019, Kabul Tarihi: 08.05.2020 
gerilme artış1; yüklü alanın boyutlarına, zeminin özelliklerine ve uygulanan yükün büyüklügüne bağlı olarak değişmektedir [1].

Literatürde genellikle zeminin sıkılığına ve uygulanan dış yükün büyüklügüne bağlı olarak zemin içerisinde meydana gelen gerilme dağılımının ölçülmesi için model deneyler oluşturulmuş ve elde edilen sonuçlar, sonlu elemanlar yöntemlerinden elde edilen sonuçlar ile ve Boussinesq [2] ve Westergaard [3] tarafindan önerilen yöntemlerden elde edilen sonuçlar ile karşılaştırılmıştır.

Çiçek vd. [1], bir kum yatağı üzerindeki üniform yüklü bir şerit temelin merkezi altında meydana gelen düşey gerilme değerlerini veren bir laboratuar model deneyi geliştirmişler ve orta sık1 kumdaki düşey gerilme dağılımını küçük basınç sensörleri kullanarak ölçmüşlerdir. Ayrıca modele ait düşey gerilme artışlarını bir sonlu elemanlar yazılımı yardımı ile ve geleneksel yöntemlerle belirleyerek sonuçları karşılaştırmışlardır. Araştırmacılar, özellikle hesap derinliğinin temel genişliğine oranının 1'den küçük olduğu derinliklerde deneysel sonuçların Westergaard [3] yönteminden elde edilen sonuçlara çok yakın olduğunu, buna karşılık nihai taşıma kapasitesine ulaşıldıktan sonra deneysel sonuçların Boussinesq [2] yönteminden elde edilenlere daha yakın olduğunu ifade etmişlerdir. Ayrıca sonlu elemanlar modelinden elde edilen gerilmelerin, ölçülen ve geleneksel yöntemlerden elde edilenler gerilmelerden daha büyük değerlere sahip olduğunu gözlemlemişlerdir.

Laman ve Keskin [4], kare temelin altında kumlu bir zemin içerisinde oluşacak ilave düşey gerilme artışlarını farklı iki sıkılığa sahip kum zemin için incelemişlerdir. Bu amaçla bir model deney oluşturmuşlar ve farklı sıkılığa sahip iki kum zemin içerisinde farklı yükleme kademeleri altında ve belirli derinliklerde oluşan ilave düşey gerilmeleri belirlemişlerdir. Aynı modele ait gerilme artışlarını sonlu elemanlar yazılımı ve geleneksel yöntemler ile de hesaplamışlardır. Elde edilen sonuçlar karşılaştırıldığında Hardening Soil ve Mohr Coulomb zemin modelleri ile yapılan sonlu elemanlar analizlerinden elde edilen sonuçlar ile deneysel sonuçların uyum içerisinde olduğu görülmüştür. Bazı yükleme durumlarında Boussinesq [2] tarafından önerilen yöntem ile bulunan sonuçların yakın olduğu ve Westergaard [3] tarafindan önerilen yöntem ile bulunan sonuçların diğer yöntemlere nispeten daha küçük sonuçlar verdiği gözlemlenmiştir. Ayrıca araştırmacılar, yaptıkları deneyler sonucunda, aynı yükleme altında aynı hesap derinliğinde bulunan ilave düşey gerilmelerin, zeminin sıkılık değerinin artması ile arttığını gözlemlemiş̧lerdir.

Keskin vd. [5], kumlu bir zemin üzerindeki üniform yüklü kare bir temelin merkezi altında meydana gelen düşey gerilme değerlerini deneysel ve nümerik olarak belirlemişler ve elde ettikleri sonuçları Boussinesq [2] yönteminden elde edilen sonuçlar ile karşılaştırmışlardır. Sonuç olarak sonlu elemanlar yöntemi ile teorik yöntemlerden elde edilen sonuçların, özellikle temel genişliğinin iki katına eşit olan derinlik içerisinde uyumlu olduğu ve Boussinesq [2] yönteminin ise zemin yüzeyine uygulanan gerilmenin büyüklügünün \%10'una düştüğü derinlik içerisinde hem deneysel hem de sonlu elemanlar yöntemi sonuçlarıyla uyum içerisinde olduğu ifade edilmiştir.

Birçok araştırmacı üniform yüklü dikdörtgen bir alan altında meydana gelen gerilmelerin hesaplanabilmesi için ampirik eşitlikler önermişlerdir [6-8].

$\mathrm{Bu}$ çalışma kapsamında belli bir üniform yayılı yük altında meydana gelen ilave düşey gerilmeye zemin özelliklerinin ve temel boyutlarının etkisi incelenmiştir. Bu amaçla $1 \mathrm{mx} 1 \mathrm{~m}, 4 \mathrm{mx} 1 \mathrm{~m}$ ve $10 \mathrm{mx} 1 \mathrm{~m}$ boyutlarındaki temeller, içsel sürtünme açlları $10^{\circ}, 20^{\circ}, 30^{\circ}$ ve $40^{\circ}$ olan kum zemin üzerine oturtularak zemin içerisindeki ilave düşey gerilmelerin değişimleri araştırılmıştır. İlave düşey gerilme hesapları, iki boyutlu bir sonlu elemanlar yazılımı olan Plaxis 2D ile ve geleneksel zemin mekaniğinde yaygın bir şekilde kullanılan Boussinesq [2], Westergaard [3] yöntemi ve yaklaşık yöntem ile gerçekleştirilmiş ve elde edilen sonuçlar karşılaştırılmıştır.

\section{Materyal ve Metot}

Literatürde yüklü bir alan altındaki gerilme artışlarının hesabı için önerilen birçok yöntem bulunmaktadır. Bu çalışma kapsamında kullanılacak temeller altındaki gerilme artışlarının hesabında kullanılmaya en uygun yöntemler üniform dikdörtgen yüklü ve üniform şerit yüklü bir alan altında gerilme hesabı yapan yöntemlerdir. Şerit yükleme altında meydana gelen gerilme artışlarının hesabı için kullanılan yöntemlerde "Sonlu genişlik ve sonsuz uzunluk $(\mathrm{L} / \mathrm{B}=\infty)$ " tarifi kullanılmaktadır [9]. Ayrıca şerit veya dikdörtgen yüklü alan altındaki gerilme artışlarının hesabı için kullanılan yöntemlerde L/B oranı için bir sınırdan net olarak bahsedilmemiştir. Bu nedenle bu çalışmada tüm temel durumları için üniform dikdörtgen yüklü alan altındaki gerilme artışını hesaplayan yöntemler dikkate alınmıştır. 


\subsection{Boussinesq yöntemi}

İlave düşey gerilmelerin belirlenmesinde yaygın bir şekilde kullanılan ve elastisite teorisi kullanılarak oluşturulan pratik çözümlerden birisi Boussinesq [2] yöntemidir. Bu yöntem, Şekil 1'de gösterildiği gibi L uzunluğuna ve $B$ genişliğine sahip esnek ve üniform yüklü dikdörtgen bir alanın köşesi altında herhangi bir A noktasındaki düşey gerilmenin hesaplanmasına olanak tanımaktadır.

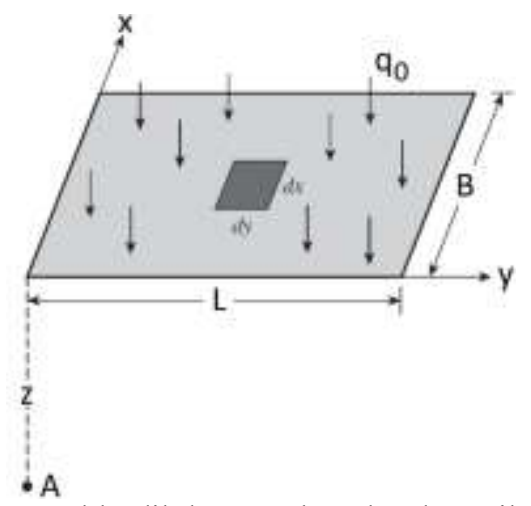

Şekil 1. Esnek ve üniform yüklü dikdörgen alan altında gerilmenin belirlenmesi [10]

Bu yönteme göre üniform yüklü dikdörtgen bir alan altında herhangi bir A noktasındaki toplam gerilme artışı $\Delta \sigma$, Eşitlik (1)'den hesaplanmaktadır.

$$
\begin{aligned}
& \Delta \sigma=\mathrm{q}_{0} * \mathrm{I} \\
& \mathrm{I}=\frac{1}{4 \pi}\left(\frac{2 \mathrm{mn} \sqrt{\mathrm{m}^{2}+\mathrm{n}^{2}+1}}{\mathrm{~m}^{2}+\mathrm{n}^{2}+\mathrm{m}^{2} \mathrm{n}^{2}+1} * \frac{\mathrm{m}^{2}+\mathrm{n}^{2}+2}{\mathrm{~m}^{2}+\mathrm{n}^{2}+1}+\tan ^{-1} \frac{2 \mathrm{mn} \sqrt{\mathrm{m}^{2}+\mathrm{n}^{2}+1}}{\mathrm{~m}^{2}+\mathrm{n}^{2}-\mathrm{m}^{2} \mathrm{n}^{2}+1}\right) \\
& \mathrm{m}=\frac{\mathrm{B}}{\mathrm{z}} \\
& \mathrm{n}=\frac{\mathrm{L}}{\mathrm{z}}
\end{aligned}
$$

Eşitlik (2)'deki ters trigonometrik fonksiyon içerisindeki ifadenin birimi radyandır ve eğer bu ifade negatif çıkarsa bu terime $\pi$ eklenmelidir. Burada $\mathrm{q}_{0}$, net taban basıncını temsil etmektedir.

\subsection{Westergaard yöntemi}

Westergaard [3], üniform yüklü esnek bir dikdörtgen alan altındaki herhangi bir noktada meydana gelen ilave düşey gerilmenin hesaplanabilmesi için, Boussinesq [2] tarafindan önerilen yöntemi modifiye ederek zeminin poisson oranını da dikkate alan Eşitlik (5)'i önermiştir [9].

$$
\begin{aligned}
& \Delta \sigma=\frac{\mathrm{q}_{0}}{2 \pi}\left(\cot ^{-1} \sqrt{\eta^{2}\left(\frac{1}{\mathrm{~m}^{2}}+\frac{1}{\mathrm{n}^{2}}\right)+\eta^{4}\left(\frac{1}{\mathrm{~m}^{2} \mathrm{n}^{2}}\right)}\right) \\
& \eta=\sqrt{\frac{1-2 \mu_{\mathrm{s}}}{2-2 \mu_{\mathrm{s}}}}
\end{aligned}
$$

Eşitlik (5)’teki m ve n değerleri de Eşitlik (3) ve Eşitlik (4)'ten hesaplanmaktadır. Burada $\mu_{s}$, zeminin poisson oranıdır. 


\subsection{Yaklaşık yöntem (2:1 yöntem)}

Geoteknik mühendisleri, inşa edilen bir yapı tarafindan zeminde meydana gelecek ilave düşey gerilmenin derinlikle değişimini belirlemek için genellikle yaklaşık yöntemi kullanırlar [10]. Bu yöntem kullanılarak z derinliğindeki ilave düşey gerilme hesabı Şekil 2'de gösterilmiş ve hesapta kullanılacak bağıntı Eşitlik (7)'de sunulmuştur.

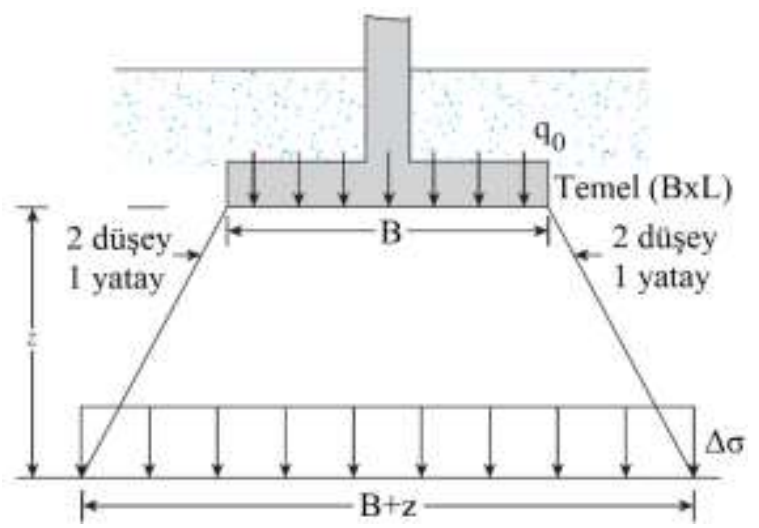

Şekil 2. Bir temel altındaki gerilme artışlarının 2:1 yöntem (yaklaşık yöntem) ile hesabı [10]

$\Delta \sigma=\frac{\mathrm{q}_{0}{ }^{*} \mathrm{~B}^{*} \mathrm{~L}}{(\mathrm{~B}+\mathrm{z}) *(\mathrm{~L}+\mathrm{z})}$

\subsection{Sonlu elemanlar yöntemi}

Yapılan çalışmada, zeminin içsel sürtünme açısındaki ve temel boyutlarındaki değişimin zemin içerisindeki gerilme dağılımı üzerine etkilerini araştırmak için bir sonlu elemanlar yazılımı olan Plaxis 2D kullanılmıştır. Kurulan modellerde zemin davranışı, derinlikle artan rijitlik değerlerini dikkate alması ile gerçek zemin davranışına daha yakın bir model oluşturulmasına yardımcı olduğu için Hardening Soil modeli olarak seçilmiş ve analizler düzlemsel şekil değiştirme koşullarında gerçekleştirilmiştir. Bu modelde kullanılan zemin parametreleri Tablo 1'de verilmiştir. Analizlerde dört farklı içsel sürtünme açısı için $\left(\varnothing=10^{\circ}, 20^{\circ}, 30^{\circ}\right.$ ve $\left.40^{\circ}\right)$ zemin modeli oluşturulmuş ve her bir durum için drenajlı analizler kullanılmıştır.

Tablo 1. Zemin elemanının modellenmesinde kullanılan girdi parametreleri

\begin{tabular}{|l|c|c|c|}
\hline Parametre & Sembol & Birim & Değeri \\
\hline Sekant rijitlik & $\mathrm{E}_{50}^{\text {ref }}$ & $\mathrm{kN} / \mathrm{m}^{2}$ & 30000 \\
\hline Tanjant rijitlik & $\mathrm{E}_{\text {oed }}^{\text {ref }}$ & $\mathrm{kN} / \mathrm{m}^{2}$ & 30000 \\
\hline Yükleme-boşaltma rijitliği & $\mathrm{E}_{\mathrm{ur}}^{\text {ref }}$ & $\mathrm{kN} / \mathrm{m}^{2}$ & 90000 \\
\hline Elastisite modülü değişim katsayısı & $\mathrm{m}$ & - & 0.5 \\
\hline Poisson oranı & $\mu_{\mathrm{ur}}$ & - & 0.2 \\
\hline Zeminin doygun olmayan birim hacim ağırlığı & $\gamma_{\mathrm{n}}$ & $\mathrm{kN} / \mathrm{m}^{3}$ & 18 \\
\hline
\end{tabular}

Girdi parametrelerinden biri olan dilatansi açısı $(\varphi)$ Eşitlik (8)'den hesaplanmıştır [11]:

$\varphi=\emptyset^{\circ}-30^{\circ}$

Yüzeysel temeller için Brinkgreve'in [12] Şekil 3'teki önerisi doğrultusunda, analizlerdeki model sınırları, yatayda toplam $90 \mathrm{~m}$ ve düşeyde toplam 40 m olacak şekilde seçilmiştir. 


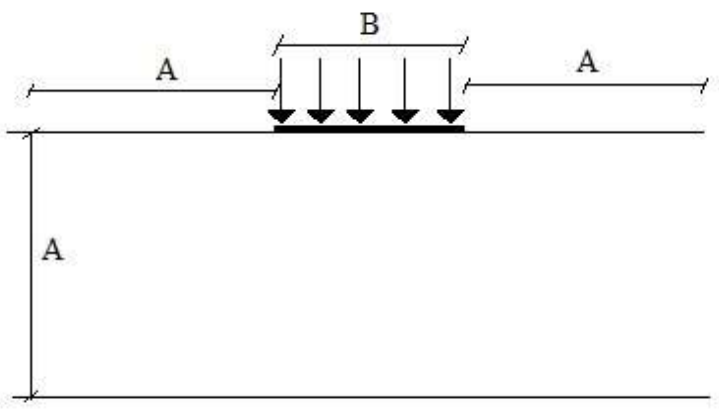

Stabilite için; $\mathrm{A} \geq 2 \mathrm{~B}$

Drenajlı deformasyon için; $A \geq 3 B$

Drenajsız deformasyon için; $A \geq 4 B$

Şekil 3. Yüzeysel temellerde model sınırları [11]

Yapılan analizlerde dikdörtgen yüklü alanın boyutları ve ilave düşey gerilme artışı arasındaki ilişkiyi inceleyebilmek için $1 \mathrm{mx} 1 \mathrm{~m}, 4 \mathrm{mx} 1 \mathrm{~m}$ ve $10 \mathrm{mx} 1 \mathrm{~m}$ olmak üzere üç farklı temel boyutunda çalışılmıştır. Temel, levha eleman olarak modellenmiş ve bu eleman üzerine tüm durumlar için üniform 10 kPa'llk yük etkitilmiştir. Temel malzemesine ait girdi parametreleri Tablo 2'de verilmiştir.

Tablo 2. Temelin modellenmesinde kullanılan girdi parametreleri

\begin{tabular}{|l|c|c|c|}
\hline Parametre & Sembol & Birim & Değeri \\
\hline Malzeme türü & - & - & Elastik, izotrop \\
\hline Normal rijitlik & EA & $\mathrm{kN} / \mathrm{m}$ & 19200000 \\
\hline Eğilme rijitliği & EI & $\mathrm{kNm} / \mathrm{m}$ & 576000 \\
\hline A ğırlı & $\mathrm{w}$ & - & 0 \\
\hline Poisson oranı & $\mu$ & $\mathrm{kN} / \mathrm{m}$ & 0 \\
\hline
\end{tabular}

Oluşturulan modelde sık üçgensel ağ(mesh) kullanılmıştır (Şekil 4). Daha sonra aşamalı inşaat analizi kullanılarak hesaplamalar yapılmış, temelin köşe noktası ve orta noktası altında gerilmenin derinlik ile değişimi belirlenmiştir.

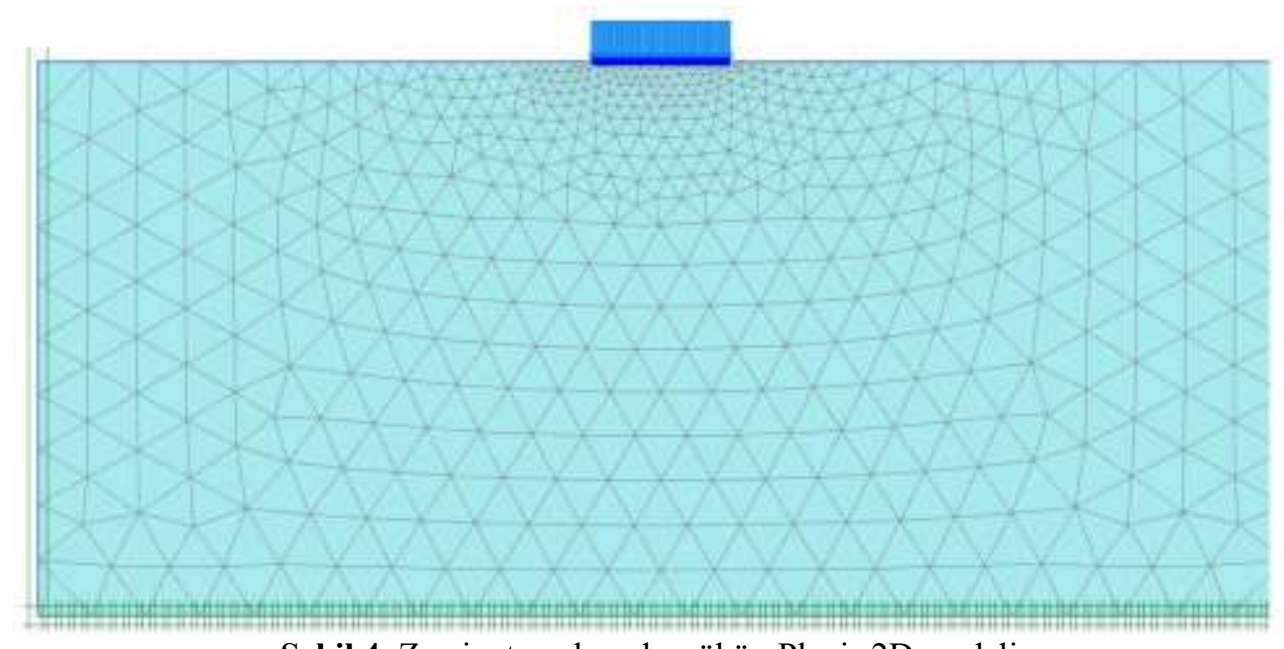

Şekil 4. Zemin, temel ve dış yükün Plaxis 2D modeli

\section{Bulgular ve Tartışma}

Farklı boyutlara sahip temeller altında farklı içsel sürtünme açısına sahip zeminler içerisinde ilave düşey gerilmenin derinlikle değişiminin sonlu elemanlar analizi ile incelenmesi sonucunda temelin köşe ve orta noktası altında elde edilen değerler sırasıyla Şekil (5) ve Şekil (6)'te verilmiştir. 


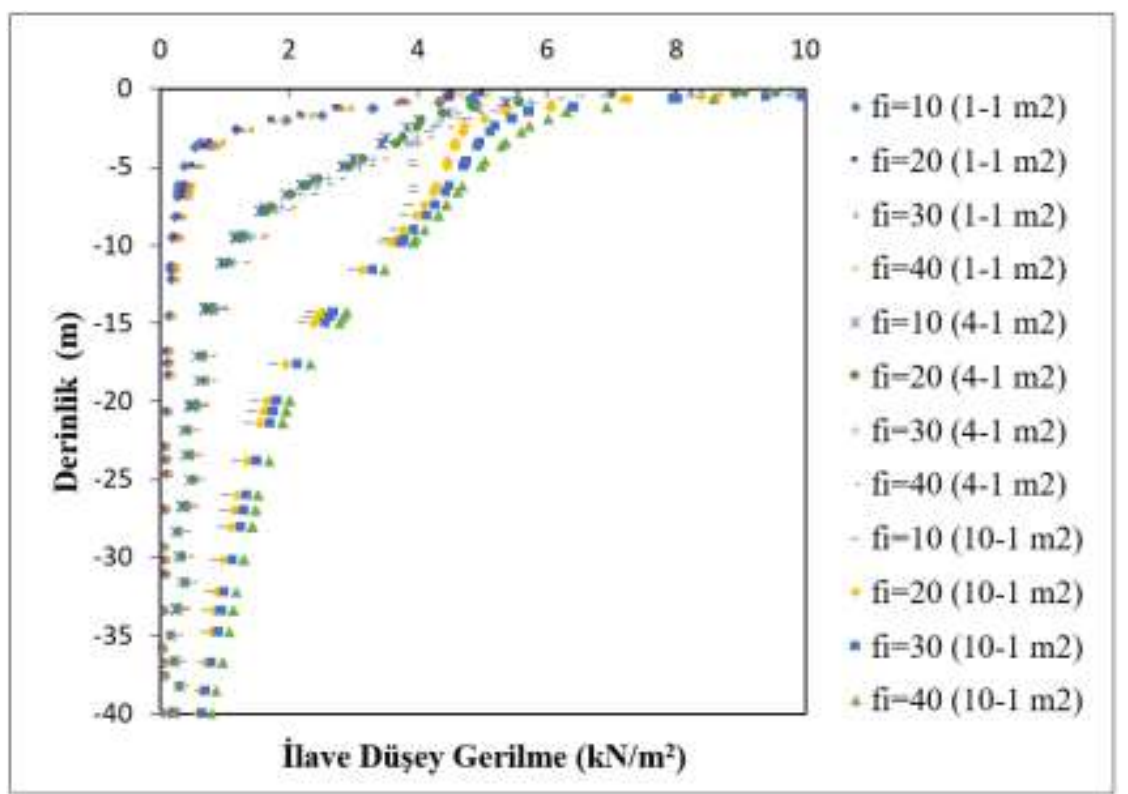

Şekil 5. Sonlu elemanlar analizlerinden elde edilen temelin köşesi altındaki ilave düşey gerilmenin derinlikle değişimi

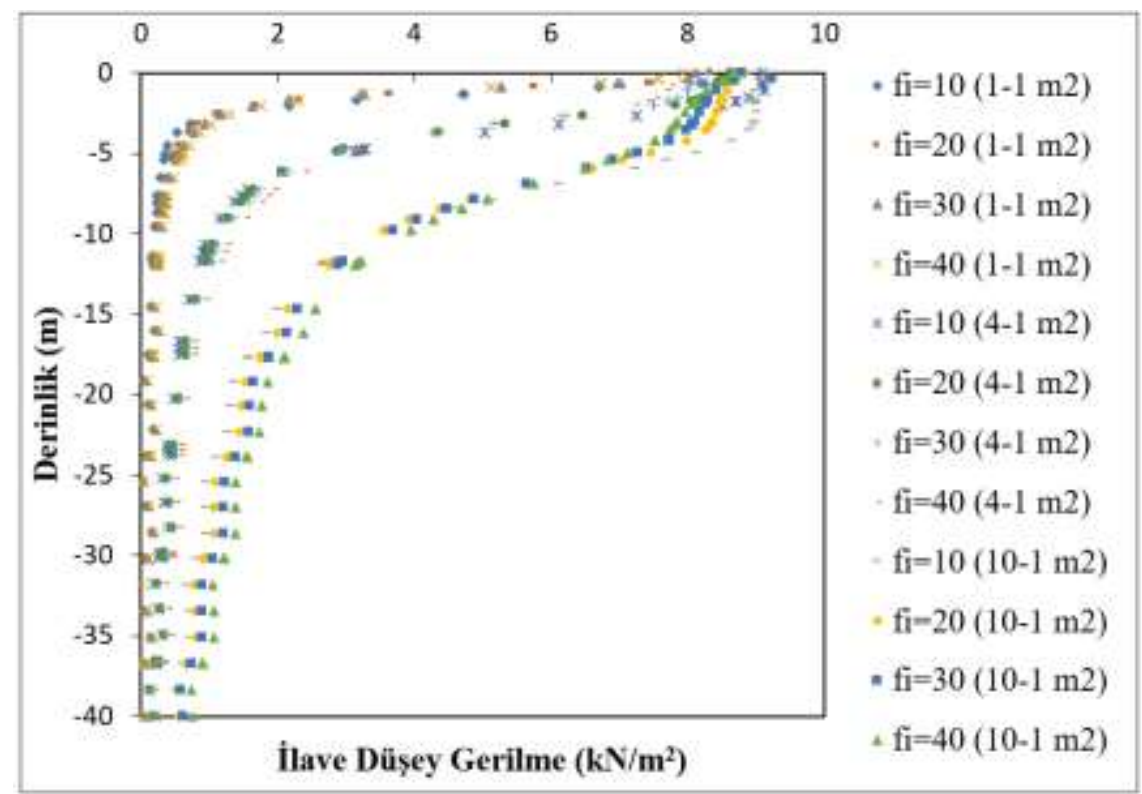

Şekil 6. Sonlu elemanlar analizlerinden elde edilen temelin orta noktası altındaki ilave düşey gerilmenin derinlikle değişimi

Sonlu elemanlar yönteminden elde edilen ve Şekil (5) ve Şekil (6)'da verilen sonuçlar incelendiğinde temel boyutunun artması ile ilave düşey gerilmelerin arttı̆̆ görülmektedir. Ayrıca temel boyutu büyüdükçe zeminin içsel sürtünme açısının değişiminin ilave düşey gerilme üzerindeki etkisi daha belirgin olmaya başlamaktadır. Analizlerde temelde konveks biçimli şekil değiştirme davranışı meydana geldiği için, zeminin içsel sürtünme açısındaki azalma sonucu temelin orta noktası altındaki deformasyonlar artmakta ve bunun sonucunda temelin konveksliği artmaktadır. Bu davranışın bir sonucu olarak temelin köşe noktası altında herhangi bir derinlikteki zemin elemanında meydana gelen ilave düşey gerilmeler, içsel sürtünme açısındaki azalma sonucu azalmaktadır. Öte yandan temelin orta noktası için Şekil (6) incelendiğinde, belirli bir derinliğe kadar içsel sürtünme açısında meydana gelen artışın ilave düşey gerilme üzerinde azaltıcı etkiye sahip olduğu, bu derinlikten sonra ise tam tersi durumun oluştuğu görülmektedir. Bu davranışın dönüm noktasının 10-1 $\mathrm{m}^{2}$ temel için temel uzunluğunun (L) 1 katına, 4-1 $\mathrm{m}^{2}$ temel için temel uzunluğunun 1,25 katına ve 1-1 $\mathrm{m}^{2}$ temel için temel uzunluğunun 2,5 katına eşit olduğu derinlik içerisinde meydana geldiği gözlemlenmiştir. Temel 
uzunluğunun 1 2.5 katına eşit olan ve deformasyonların daha yüksek olduğu bu derinlik boyunca, temelin orta noktası ve köşe noktası altında ilave gerilme dağılımı üzerine içsel sürtünme açısının farklı etki yapmasına temelin elastik davranışının neden olduğu düşünülmektedir. Genel olarak zeminin içsel sürtünme açısının artması ile temel altındaki zeminin dayanımı artmakta ve bunun bir sonucu olarak zemin, aynı yükleme altında daha düşük içsel sürtünme açılarına göre daha az deformasyona maruz kalmaktadır. Bu sebeple temelin orta noktası altında deformasyonların yoğunlaştığı ve nispeten daha büyük değerlere sahip olduğu derinlik içerisinde $(\mathrm{L} \sim 2.5 \mathrm{~L})$ içsel sürtünme açısının artması ile gerilmeler azalmaktadır.

Temelin köşe ve orta noktası altında meydana gelen ilave düşey gerilme artışlarının teorik ve nümerik sonuçlarının karşılaştırmasını veren grafikler aşağıda sunulmuştur (Şekil (7), Şekil (8), Şekil (9), Şekil (10), Şekil (11), Şekil (12)).

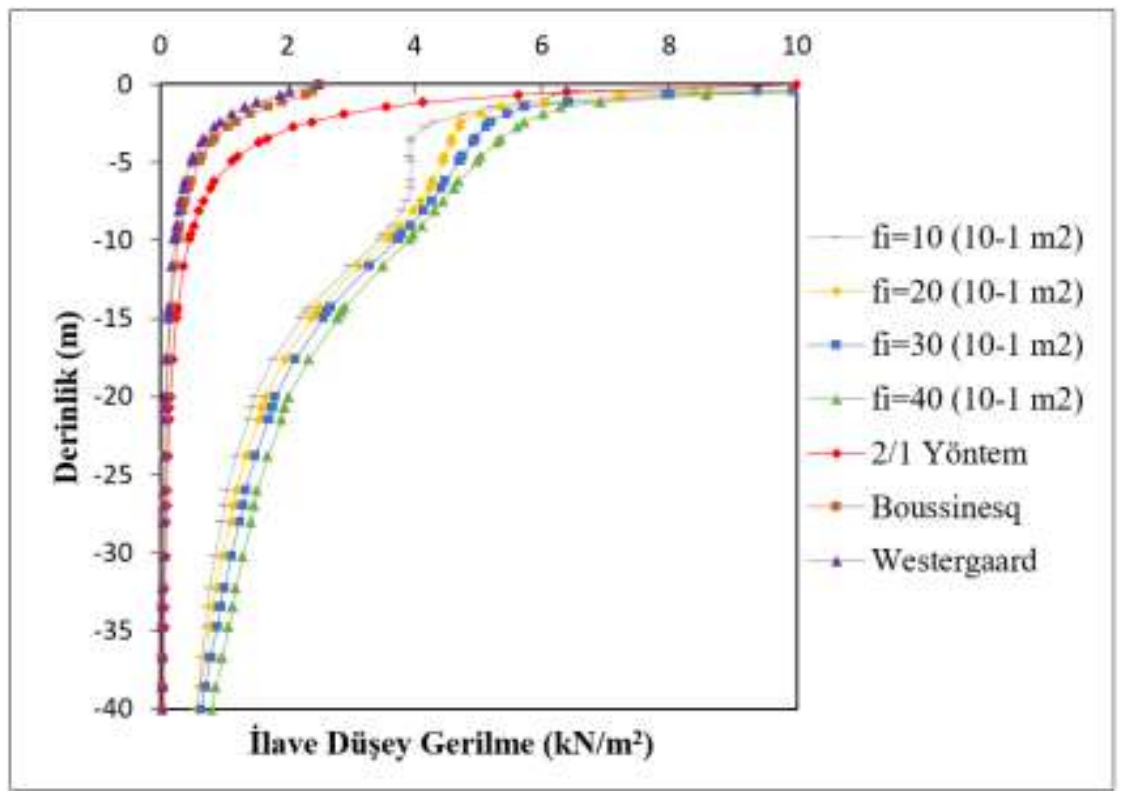

Şekil 7. İlave düşey gerilmenin 10-1 $\mathrm{m}^{2}$ alana sahip temelin köşe noktası altındaki dağılımının teorik ve nümerik analizlerden elde edilen sonuçlarının karşılaştırılması

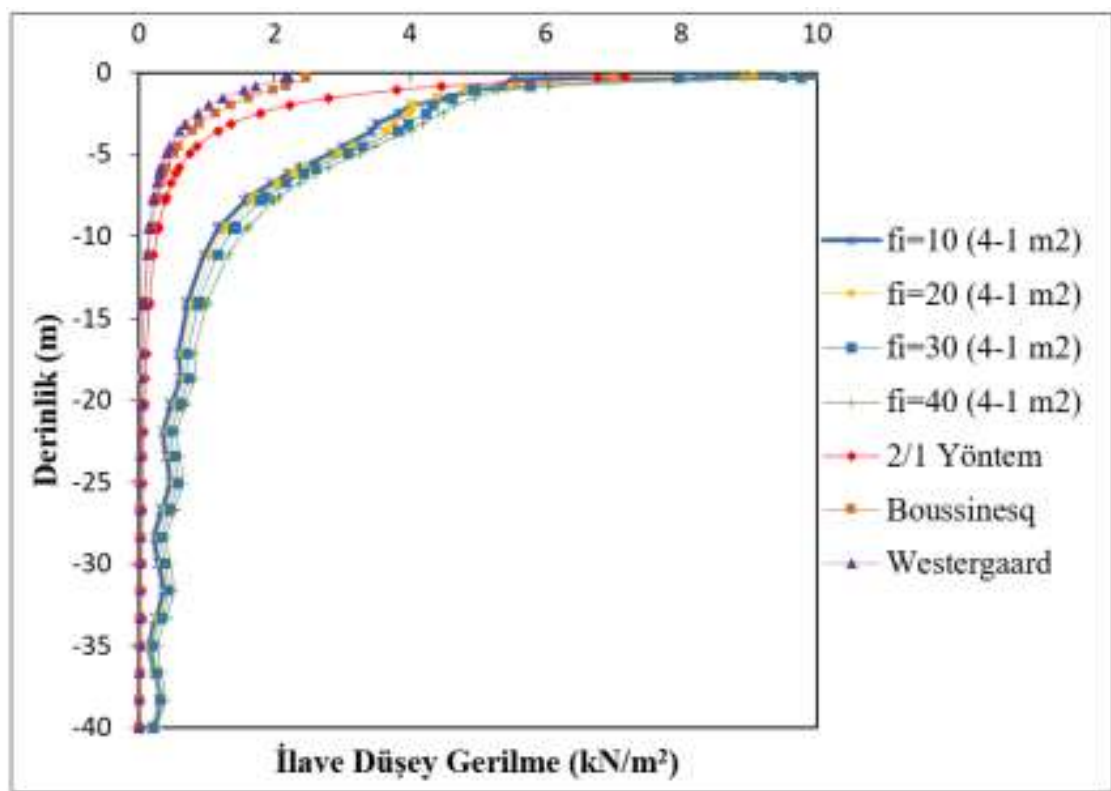

Şekil 8. İlave düşey gerilmenin 4-1 $\mathrm{m}^{2}$ alana sahip temelin köşe noktası altındaki dağılımının teorik ve nümerik analizlerden elde edilen sonuçlarının karşıllaştırılması 


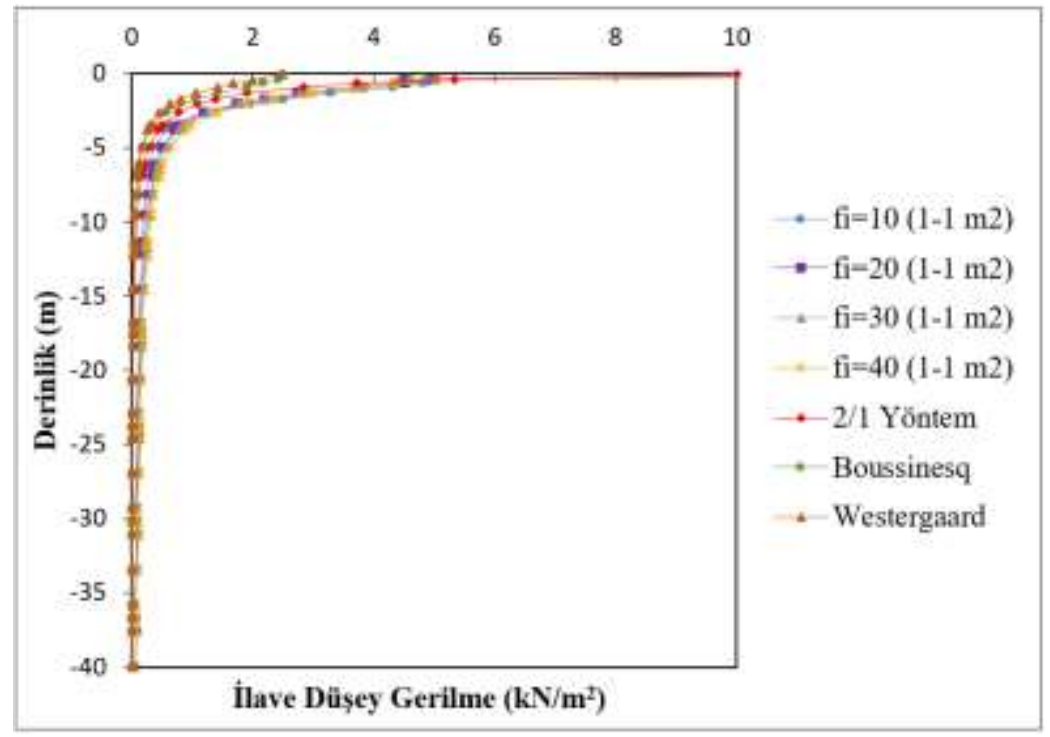

Şekil 9. İlave düşey gerilmenin 1-1 $\mathrm{m}^{2}$ alana sahip temelin köşe noktası altındaki dağılımının teorik ve nümerik analizlerden elde edilen sonuçlarının karşılaştırılması

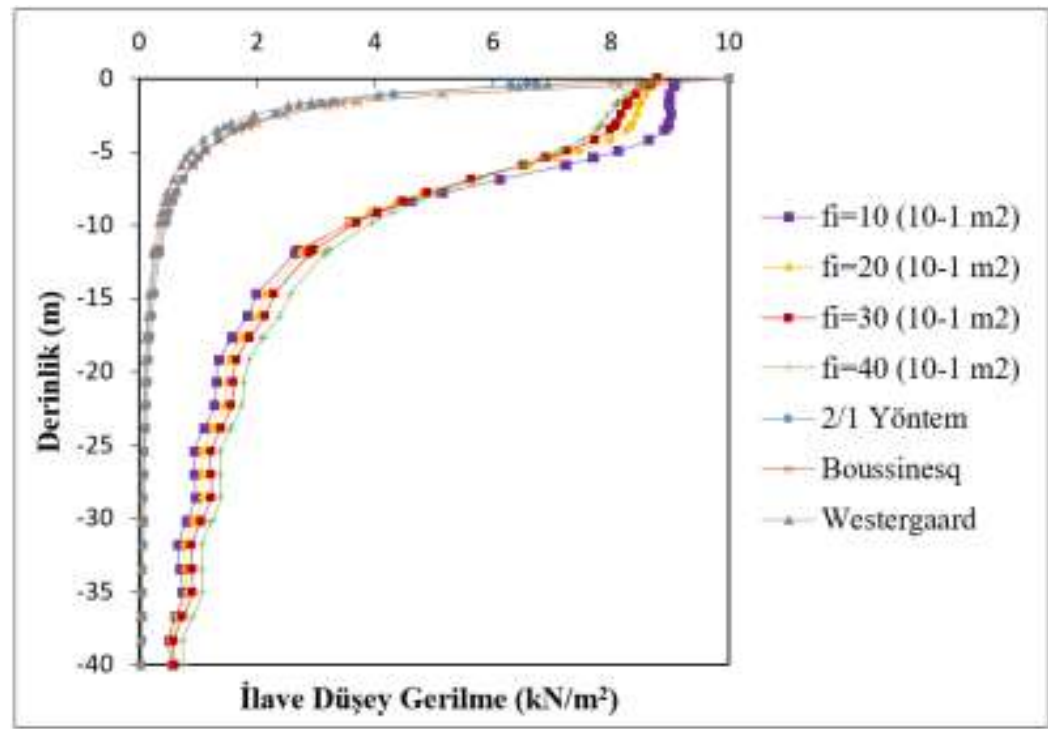

Şekil 10. İlave düşey gerilmenin $10-1 \mathrm{~m}^{2}$ alana sahip temelin orta noktası altındaki dağılımı

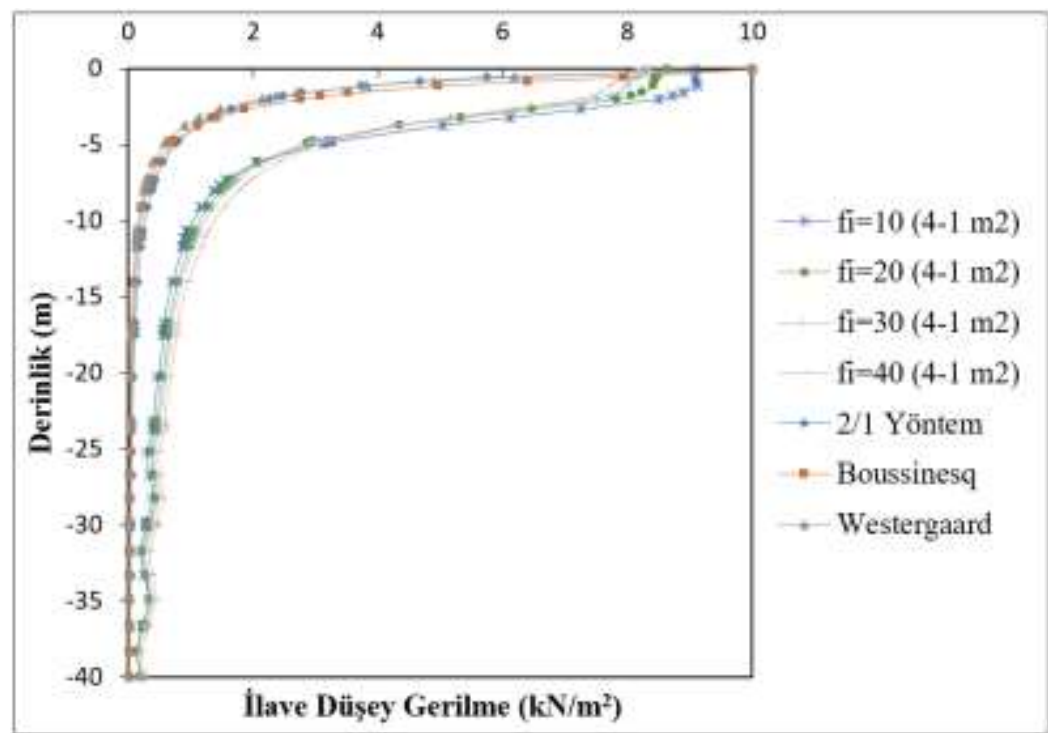

Şekil 11. İlave düşey gerilmenin $4-1 \mathrm{~m}^{2}$ alana sahip temelin orta noktası altındaki dağılımı 


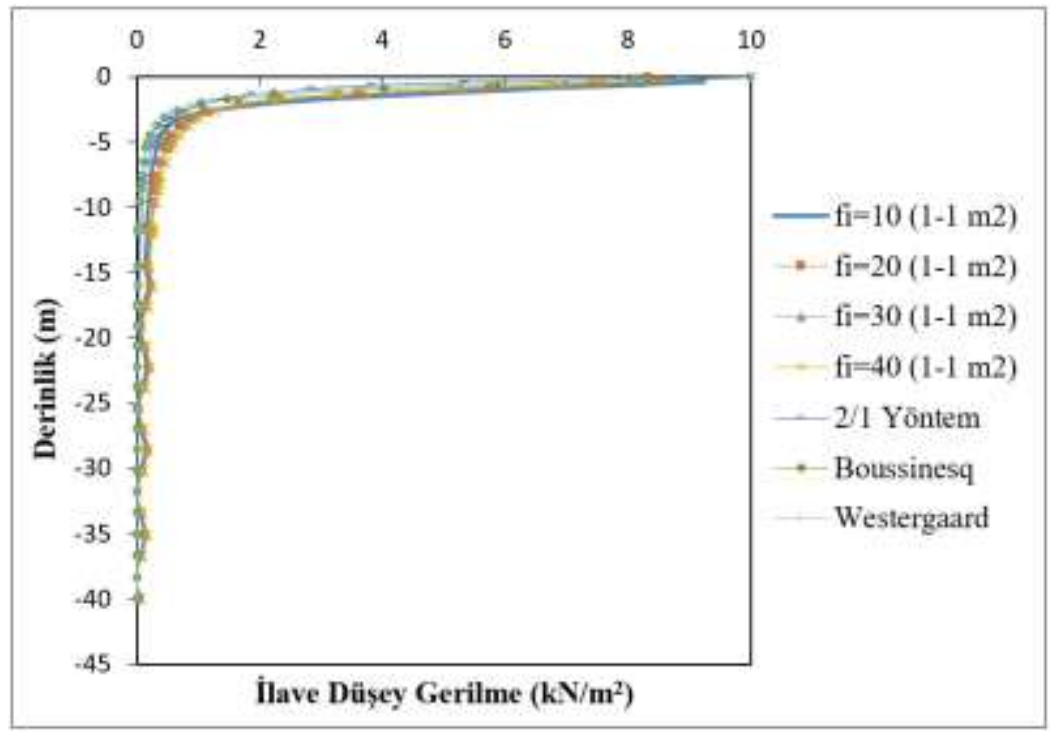

Şekil 12. İlave düşey gerilmenin 1-1 $\mathrm{m}^{2}$ alana sahip temelin orta noktası altındaki dağılımı

Aynı derinlikteki zemin enkesitinde, genel olarak sonlu elemanlar analizleri diğer yöntemlere kıyasla daha büyük ilave düşey gerilmeler vermektedir. Temel boyutları küçüldükçe sonlu elemanlar yönteminden elde edilen sonuçlar, Westergaard [3], Boussinesq [2] ve yaklaşık yöntemden elde edilen sonuçlara yaklaşmaktadır. Yine temel boyutunun küçülmesi sonucu sonlu elemanlar yöntemine ait ilave gerilme dağılımı davranışı ile klasik teorilerden elde edilen gerilme dağılımı davranışları arasındaki uyum artmaktadır.

Temelin köșe noktası altında sonlu elemanlar analizi ile belirlenen ilave düşey gerilmelere en yakın sonuçları yaklaşık yöntem vermiştir. Bu yöntemin içsel sürtünme açısı düşük olan zeminler için daha gerçekçi sonuç verdiği söylenebilir.

Temelin orta noktası altında sonlu elemanlar analizi ile belirlenen ilave düşey gerilmelere en yakın sonuçları;

i. Deformasyonların büyük ve yoğun olduğu derinlik içerisinde (L 2.5L) Boussinesq [2] yönteminin verdiği ve bu yöntemin zeminin içsel sürtünme açısı büyüdükçe daha gerçekçi sonuçlar verdiği,

ii. Bu derinliğin altında ise yaklaşık yöntemin verdiği ve bu yöntemin zeminin içsel sürtünme açısı küçüldükçe daha gerçekçi sonuçlar verdiği söylenebilir.

\section{Sonuçlar}

Temel boyutlarında meydana gelen değişimin ilave düşey gerilme üzerindeki etkisine göre içsel sürtünme açısındaki değişimin ilave düşey gerilme üzerindeki etkisi nispeten daha küçüktür.

Temelin orta noktası altında deformasyonların yoğunlaştığı ve nispeten daha büyük değerlere sahip olduğu derinlik içerisinde ( $\mathrm{L} \sim 2.5 \mathrm{~L})$ içsel sürtünme açısının artması ile gerilmeler azalmaktadır.

Temelin köşe noktası altında herhangi bir derinlikteki zemin elemanında meydana gelen ilave düşey gerilmeler, içsel sürtünme açısındaki azalma sonucu azalmaktadır.

Temelin orta noktası altında deformasyonların etkisinin çok az olduğu derinliklerde( $>\mathrm{L} \sim 2.5 \mathrm{~L})$, içsel sürtünme açısının artması ile ilave gerilmeler küçük artışlar göstermektedir.

İlave düşey gerilme hesaplarında yaklaşık yöntem, Boussinesq [2] ve Westergaard'a [3] göre sonlu elemanlar çözümüne daha yakın sonuçlar vermektedir.

Boussinesq [2] yönteminin, temelin orta noktası altında deformasyonların yoğun olduğu derinlik içerisinde $(\mathrm{L} \sim 2.5 \mathrm{~L})$, içsel sürtünme açısı büyüdükçe sonlu elemanlar analizlerinden elde edilen sonuçlara daha yakın sonuçlar verdiği gözlemlenmiştir.

Deformasyonların etkisinin çok az olduğu derinliklerde $(>\mathrm{L} \sim 2.5 \mathrm{~L})$ yaklaşık yöntemden elde edilen sonuçlar içsel sürtünme açısı küçüldükçe sonlu elemanlar analizlerinden elde edilen sonuçlara daha yakın sonuçlar vermiştir. 
Temel boyutlarının büyümesi sonucu Westergaard [3], Boussinesq [2] ve yaklaşık yöntemden elde edilen gerilme artışları, PLAXIS 2D'de yapılan analizlerden elde edilen sonuçlara göre davranış ve büyüklük olarak farklılaşmaktadır. Buna istinaden zemin mekaniğinde yaygın bir şekilde kullanılan bu teorilerin temel boyutları küçüldükçe daha gerçekçi sonuçlar verdiği söylenebilir.

\section{Yazarların Katkısı}

Tüm yazarlar bu makalenin yazılmasında eşit katkı sağlamışlardır.

\section{Çıkar Çatışması Beyanı}

Yazarlar arasında herhangi bir çıkar çatışması bulunmamaktadır.

\section{Araştırma ve Yayın Etiği Beyanı}

Yapılan çalışmada araştırma ve yayın etiğine uyulmuştur.

\section{Kaynaklar}

[1] Çiçek E., Güler E., Yetimoğlu T. 2016. Comparison of Measured and Theoretical Pressure Distribution below Strip Footings on Sand Soil. International Journal of Geomechanics, 14 (5): $1-8$.

[2] Boussinesq J. 1885. Application des Potentiels a L'etude de L'equilbre et du Movement des Solids Elastiques. Gauthier-Villars, Paris.

[3] Westergaard H.M. 1938. A Problem of Elasticity Suggested by a Problem in Soil Mechanics: Soft Material Reinforced by Numerous Strong Horizontal Sheets, Contributions to the Mechanics of Solids. Dedicated S. Timoshenko 60th Anniversary Volume: 268-277.

[4] Laman M., Keskin M.S. 2004. Kumlu Zeminlere Oturan Kare Temeller Altında Düşey Gerilme Analizi. Türkiye Mühendislik Haberleri, 431: 53-57.

[5] Keskin M.S., Laman M., Baran T. 2008. Kuma Oturan Kare Temeller Altında Oluşan Düşey Gerilmelerin Deneysel Tespiti ve Sayısal Analizi. İMO Teknik Dergi, 299: 4521-4538.

[6] Algin H.M. 2000. Stress from Linearly Distributed Pressures over Rectangular Areas. International Journal for Numerical and Analytical Methods in Geomechanics, 24: 681-692.

[7] Gray H. 1943. Stress and Displacement from Loads over Rectangular Areas. Civil Engineering, ASCE, 13 (5): 227-229.

[8] Vitone D.M.A., Valsangkar A.J. 1986. Stress from Loads Over Rectangular Areas. Journal of Geotechnical Engineering, 112 (10): 961-964.

[9] DAS B.M., Sobhan K. 2018. Principle of Geotechnical Engineering Ninth Edition. Global Engineering, Cengage Learning, United States of America, 1-819.

[10] DAS B.M. 2011. Principle of Foundation Engineering 7th Edition. Global Engineering, Cengage Learning, United States of America, 1-794.

[11] Plaxis 2D Material Models Manual 2019.

[12] Brinkgreve R. 2005. Computational Geotechnics for Experienced Users (Plaxis). 